\title{
SDFI-3'A polymorphism is associated with increased risk of hematological malignancy: a meta-analysis
}

This article was published in the following Dove Press journal:

OncoTargets and Therapy

14 March 2017

Number of times this article has been viewed

\section{Xiaowen Zhang \\ Yang Fan}

Zhijie Li

Medical Research Center, Shengjing Hospital of China Medical University, Shenyang, China
Correspondence: Zhijie Li Medical Research Center, Shengjing Hospital of China Medical University, 36 Sanhao Street, Heping District, Shenyang I I 0004, China Tel +86 I8940259465 Fax +86 02496619 I3429 Email lizhijie68@hotmail.com
Abstract: $C X C L 12$ (also named $S D F 1$ ), a member of the chemokine family, has been demonstrated to play an important role in the progression of multiple types of hematological malignancy. Several recent studies have shown that SDF1-3'A polymorphism (rs1801157) is associated with susceptibility to hematological malignancy, but published studies' results are disputed. Therefore, we performed a meta-analysis to evaluate the relationship between SDF1-3'A polymorphism and the risk of hematological malignancy based on the existing literature. We carried out a comprehensive literature search using the Web of Science, PubMed, Cochrane Library, Chinese Wan Fang, and Chinese National Knowledge Infrastructure databases. And the raw data were extracted and calculated in standard steps of meta-analysis. Overall, nine qualified studies containing 1,576 cases and 1,674 controls were included in the ultimate meta-analysis. The pooled results displayed that AA genotype significantly increased the risk of hematological malignancy. The result of subgroup analysis further indicated that $S D F 1-3^{\prime} \mathrm{A}$ polymorphism was significantly associated with increased risk of chronic myeloid leukemia, Hodgkin's lymphoma and multiple myeloma, but was not associated with increased risk of acute myeloid leukemia and non-Hodgkin's lymphoma. In addition, SDF1-3'A polymorphism was associated with increased risk of hematological malignancy in Africans and Asians, but not in Caucasians. In conclusion, our meta-analysis firstly demonstrated that $S D F 1-3^{\prime}$ A polymorphism may be associated with increased risk of hematological malignancy, especially for chronic myeloid leukemia, Hodgkin's lymphoma, multiple myeloma and the non-Caucasian population. Nevertheless, these conclusions should be reconfirmed by more evidence from large sample sized studies.

Keywords: SDF1, hematological malignancy, polymorphism, meta-analysis

\section{Introduction}

Cancer is considered as a major public health problem and one of the leading causes of death worldwide. ${ }^{1}$ Hematological malignancies, including leukemia, lymphoma, and other types, ${ }^{2}$ are in the top 10 causes of cancer death. ${ }^{3}$ According to the report from the American Cancer Society, leukemia accounted for an estimated 265,500 deaths and non-Hodgkin's lymphoma (NHL) accounted for an estimated 199,700 deaths worldwide in 2012, respectively. ${ }^{3}$ It is widely accepted that genetic variants, environmental factors, and the interaction of genetic and environmental factors are responsible for the occurrence and progression of hematological malignancy. ${ }^{4,5}$

Chemokines, a family of small cytokines, usually act as chemoattractants to manage the migration of leukocytes in the respective anatomical locations in inflammatory and homeostatic processes. ${ }^{6,7}$ Chemokine CXCL12, also named SDF-1, is a member of chemokine family and functions as the ligand for the chemokine CXCR4 to regulate 
the process of embryogenesis,${ }^{8}$ immune surveillance, ${ }^{9}$ inflammation response, ${ }^{10}$ neutrophil homeostasis, ${ }^{11}$ and tumor growth and metastasis. ${ }^{12}$ Moreover, several recent studies have shown that CXCL12/CXCR4 axis can play an important role in the progression of acute myeloid leukemia (AML), ${ }^{13,14}$ acute lymphoblastic leukemia (ALL), and chronic lymphocytic leukemia (CLL). ${ }^{14,15}$ Of note, the level of SDF1 in peripheral plasma and the expression of CXCR4 in bone marrow cells of acute leukemia (AML and ALL) group are significantly higher than that of healthy control group. ${ }^{16}$ Furthermore, function experiment in vitro indicates that elevated SDF1 is associated with increased malignant potential of AML and CLL cells. ${ }^{13,15}$ In addition to leukemia, SDF1/CXCR4 axis also participates in regulating the tumor's biological behavior of NHL and multiple myeloma (MM) cells. ${ }^{17,18}$ For instance, the expression of CXCR4 and SDF1 in NHL cells is higher than normal cells and SDF1 could promote metastasis of NHL cells. ${ }^{17}$ Similarly, SDF1 could facilitate MM cell adhesion to endothelial cells and induce MM cells' migration. ${ }^{18}$

A single nucleotide polymorphism (SNP) (SDF1-3'A or rs 1801157) containing a $\mathrm{G}$ to $\mathrm{A}$ transition at position 801 is the common polymorphism in the 3-untranslated region (3'-UTR) of SDF1 gene. Although SDF1-3'A polymorphism has already been demonstrated to possibly increase the expression of $S D F 1,{ }^{19}$ whether $S D F 1-3^{\prime} \mathrm{A}$ polymorphism is associated with the risk of hematological malignancy is still controversial in the literature. ${ }^{20,21}$ Therefore, we carried out a meta-analysis to assess whether $S D F 1-3^{\prime} \mathrm{A}$ polymorphism is related to the risk of hematological malignancy.

\section{Methods}

\section{Search strategy}

A systematic literature search was performed in several electronic databases including Web of Science, PubMed, Cochrane Library, Chinese Wan Fang, and Chinese National Knowledge Infrastructure databases until October 1, 2016 using the search formula that combined "genetic polymorphism" or "single nucleotide polymorphism" or "SNP" or "gene mutation" or "genetic variants" and "stromal cellderived factor-1" or "SDF1" or "CXCL12" or "chemokine ligand 12" or "rs1801157", together with "leukemia" or "lymphoma" or "myeloma" or "hematological malignancy" or "hematological cancer" to include all relevant studies. Manual searching was supplemented with browsing references of the retrieved articles. Based on the eligibility criteria, all articles were thoroughly examined from the title, including the entire text to determine if they could be selected for the ultimate analysis. If the opinions of two reviewers were not in agreement, the rest of the authors participated in evaluating whether an individual study should be included or not.

\section{Eligibility criteria}

The three major inclusion criteria required at least: i) concerning the relationship between the SDF1 gene polymorphism and hematological malignancy; ii) case-control or cohort studies; and iii) the articles should provide the frequencies of allele and genotype or the data in the articles can be used to calculate the frequencies of allele and genotype in both cases and controls. Articles were eliminated based on the following: i) containing duplicated data or ii) reviews, case reports, or meta-analysis. All of the control subjects were recruited from a healthy population without diagnosis of cancer and HIV infection as cancer and HIV infection have been demonstrated to dramatically influence the genotype frequencies of $S D F 1-3^{\prime}$ A polymorphism in humans.

\section{Data extraction}

Data concerning author's name, year of publication, patient characteristics, number of participants in the case and control groups, genotyping method, study type, $P$-value of the Hardy-Weinberg equilibrium (HWE) test, odds ratio (OR) and $95 \%$ confidence intervals (CIs) for the risk of hematological malignancy were collected from included articles by two authors independently. The quality of included studies was evaluated with the Newcastle-Ottawa Scale (NOS) as previously described. ${ }^{22}$

\section{Statistical analysis}

Firstly, the chi-squared goodness-of-fit test was used to examine whether the genotype distributions of the SDF1-3'A polymorphism in the controls were in accordance with HWE. The strength of the relationship between the $S D F 1-3^{\prime}$ A polymorphism and hematological malignancy was estimated by ORs with their corresponding 95\% CIs. The Cochran's $Q$ statistic and $I$-squared $\left(I^{2}\right)$ metric was used to test between-study heterogeneity. Heterogeneity was considered significant when $P<0.10$ or $I^{2}>50 \%$. With heterogeneity existing, the random-effects model was performed to calculate the pooled OR of each eligible study; otherwise, the fixed-effect model was used. Generally speaking, the pooled ORs with 95\% CIs were calculated respectively under allele model, homozygote model, heterozygote model, dominant model, and recessive model. Subgroup analyses were further carried out based on ethnicity and type of hematological malignancy, 
and pooled analysis was performed only when at least 2 independent case-control studies were included. The funnel plots and Egger's linear regression test were used to analyze the publication bias. Publication bias was considered to exist when $P<0.05$. Sensitivity analysis was conducted by omitting one study at a time to examine its effect on the entire OR value, which was usually used to assess the stability of meta-analysis. Overall statistical analyses were performed using the STATA 11.0 program (StataCorp LLC, College Station, TX, USA).

\section{Ethics}

Our meta-analysis was approved by the ethical committee of China Medical University.

\section{Results}

\section{Characteristics of the included studies}

Overall, 75 potentially qualifying articles were originally confirmed in the literature search. With strict screening based on eligibility criteria, 66 articles were eliminated. To be specific, 15 articles were duplicates; 4 articles were not casecontrol studies; 7 articles were not associated with hematological malignancy; 5 articles were review articles; 28 articles were not associated with $S D F 1$ gene polymorphism; 4 articles did not concern rs 1801157; 2 articles lacked healthy control group; and 1 article did not provide sufficient data for gene frequency. 9 articles that were strictly in agreement with the eligibility criteria were ultimately included in this metaanalysis (Figure 1). ${ }^{20,21,23-29}$

Table 1 summarized the characteristics of each of the included studies. To be specific, our meta-analysis in total included 9 independent case-control studies ranging from 2006 to 2016. Six of these studies were conducted in Caucasians. NOS score of each study was no less than 7 points. The genotype distribution in the controls was in accordance with HWE.

\section{Quantitative data synthesis}

Data of 3,250 subjects (1,576 cases and 1,674 healthy controls) were pooled in the meta-analysis. The results showed that a significant association between the $S D F 1-3^{\prime} \mathrm{A}$ polymorphism and the risk of hematological malignancy was found in the homozygote model (AA vs GG: OR $=1.442$, 95\% CI $=1.019-2.039, P=0.039$ ) (Figure 2). However, no significant association between $S D F 1-3^{\prime}$ A polymorphism and the risk of hematological malignancy was shown in the allele model, dominant model, heterozygote model and recessive model (Table 2 ).

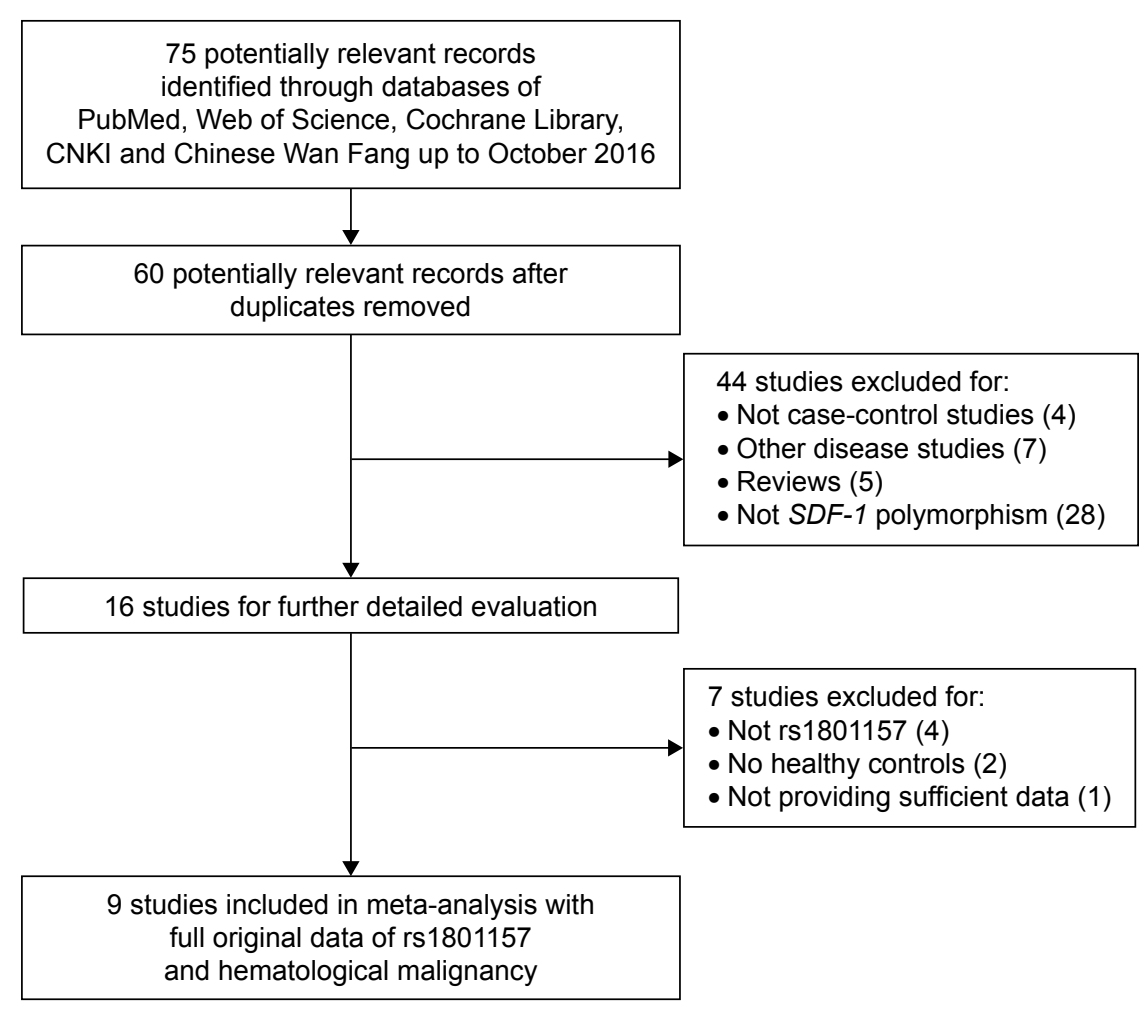

Figure I Flow diagram of the study selection process.

Abbreviation: CNKI, Chinese National Knowledge Infrastructure. 


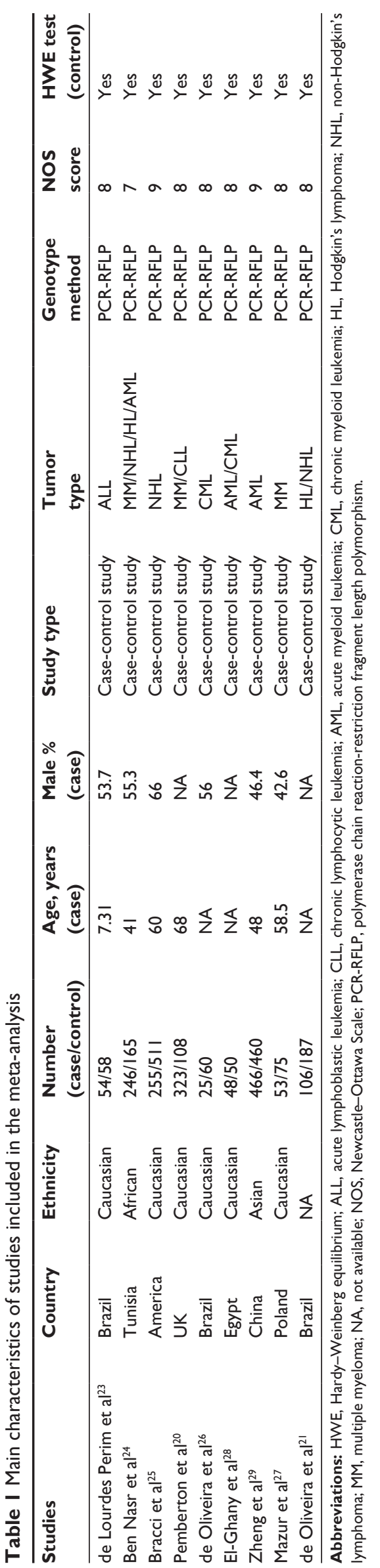

\section{Subgroup analysis}

The result of subgroup analysis by ethnicity showed that no significant relationship existed between the SDF1-3'A polymorphism and the risk of hematological malignancy in Caucasians, and the data cannot be calculated in Africans and Asians due to only one available study (Figure 3). In the subgroup analysis by type of hematological malignancy, the results showed that a significantly increased risk was displayed in the chronic myeloid leukemia (CML) subgroup in the homozygote model (AA vs GG: OR $=5.83,95 \%$ $\mathrm{CI}=1.35-25.10, P=0.018$ ) (Table 2), heterozygote model (AG vs GG: $\mathrm{OR}=2.631,95 \% \mathrm{CI}=1.138-6.084 P=0.024$ ) and dominant model (AA/AG vs GG: OR $=2.910,95 \%$ $\mathrm{CI}=1.304-6.496, P=0.009$ ) (Table 2 ). In addition, a significantly increased risk was also shown in Hodgkin's lymphoma (HL) subgroup in the homozygote model (AA vs GG: $\mathrm{OR}=3.80,95 \% \mathrm{CI}=1.63-8.86$ [Figure 4], $P=0.002$ ) (Table 2), allele model (A vs G: OR $=1.508,95 \%$ CI $=1.050-2.166$, $P=0.026$ ) and recessive model (AA vs AG/GG: $\mathrm{OR}=3.703$, 95\% CI $=1.619-8.467, P=0.002$ ) (Table 2). Meanwhile, a significantly increased risk was shown in MM subgroup in the homozygote model (AA vs GG: OR $=6.11,95 \%$ $\mathrm{CI}=2.22-16.77$ [Figure 4], $P<0.001$ [Table 2]) (Figure 4) and recessive model (AA vs $\mathrm{AG} / \mathrm{GG}$ : $\mathrm{OR}=4.038,95 \%$ $\mathrm{CI}=1.550-10.523, P=0.004)$ (Table 2). However, there was no significant statistical association between the $S D F 1-3^{\prime} \mathrm{A}$ polymorphism and the risk of hematological malignancy in the AML and NHL subgroup (Table 2).

\section{Sensitivity analysis and publication bias}

The result of sensitivity analysis revealed that the pooled OR was not considerably affected by omitting any individual study, which confirmed that our result was robust (Figure 5). The funnel plot was symmetrical by visual inspection based on dominant genetic model data (Figure 6). Egger's test suggested no publication bias for all genetic models ( $P=0.196,95 \%$ CI: $-1.830946,7.424647$ for allele model, $P=0.329,95 \%$ CI: $-2.535315,6.585456$ for homozygote model, $P=0.116,95 \%$ CI: $-0.8942766,6.540984$ for heterozygote model, $P=0.116,95 \% \mathrm{CI}:-1.072597,7.767599$ for dominant model, $P=0.314,95 \% \mathrm{CI}:-1.601126,4.317495$ for recessive model, respectively).

\section{Discussion}

The $S D F 1$ gene is located on chromosome 10q11.1. ${ }^{30} \mathrm{SDF} 1$ protein has been demonstrated to be associated with increased risk of various kinds of cancers, including breast cancer, ${ }^{31}$ lung cancer, ${ }^{32}$ bladder cancer, ${ }^{33}$ and acute leukemia. ${ }^{16}$ SDF1-3'A polymorphism is identified as a $\mathrm{G}$ to A mutation at 


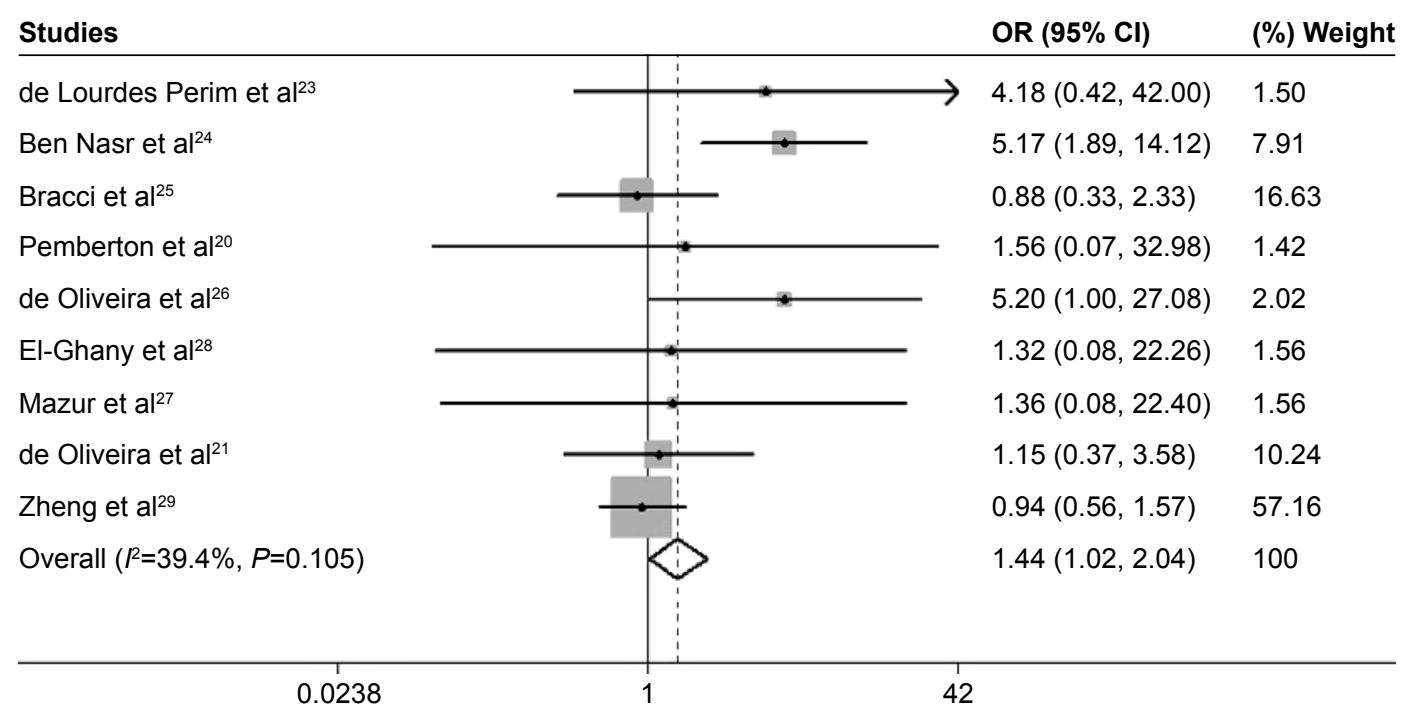

Figure 2 Forest plot of SDFI-3'A polymorphism and the risk of hematological malignancy under a homozygote genetic model (AA vs GG). Abbreviations: $\mathrm{OR}$, odds ratio; $\mathrm{Cl}$, confidence interval.

position 801 in the $3^{\prime}-\mathrm{UTR}$ region in $S D F 1 \beta$ transcriptional splice variant and $S D F 1-3^{\prime}$ A polymorphism has been confirmed to be associated with increased risk of multiple types of cancer, ${ }^{34-37}$ probably because it could increase the expression of SDF1 protein. ${ }^{19}$ Although a previous genome-wide association study (GWAS) has shown that some SNPs in SDF1 gene, such as rs 2857653 and rs2297630, were associated with increased risk of CLL, SDF1-3'A polymorphism (rs1801157) was still not included in this study ${ }^{38}$ Moreover, we also found that rs1801157 was not reported by other

Table 2 Main results of the meta-analysis of the pooled OR

\begin{tabular}{|c|c|c|c|c|c|c|}
\hline \multirow[t]{2}{*}{ Variable } & \multirow{2}{*}{$\begin{array}{l}\text { Cases/ } \\
\text { controls (n) }\end{array}$} & \multicolumn{5}{|c|}{ OR (95\% CI) P-value } \\
\hline & & $\begin{array}{l}\text { Allele } \\
\text { (A vs G) }\end{array}$ & $\begin{array}{l}\text { Homozygote } \\
\text { (AA vs GG) }\end{array}$ & $\begin{array}{l}\text { Heterozygote } \\
\text { (AG vs GG) }\end{array}$ & $\begin{array}{l}\text { Dominant } \\
\text { (AA/AG vs GG) }\end{array}$ & $\begin{array}{l}\text { Recessive } \\
\text { (AA vs AG/GG) }\end{array}$ \\
\hline \multirow[t]{2}{*}{ All subjects } & $\mathrm{I}, 576 / \mathrm{I}, 674$ & $1.234(0.946-1.610)$ & 1.442 (1.019-2.039) & $1.263(0.966-1.652)$ & $1.319(0.987-1.764)$ & I.339 (0.950-I.887) \\
\hline & & 0.121 & $0.039 a, *$ & 0.088 & 0.062 & $0.096^{a}$ \\
\hline \multicolumn{7}{|l|}{ Ethnicity } \\
\hline \multirow[t]{2}{*}{ Caucasian } & $758 / 844$ & $1.210(0.827-|.77|)$ & $\mathrm{I} .529(0.778-3.007)$ & I.I87 (0.859-I.640) & I.256 (0.880-I.793) & $1.404(0.695-2.838)$ \\
\hline & & 0.327 & $0.218^{a}$ & 0.299 & 0.210 & $0.344^{\mathrm{a}}$ \\
\hline \multirow[t]{2}{*}{ African } & $246 / 165$ & I.867 (I.368-2.548) & $5.172(1.895-14.122)$ & $1.980(1.311-2.992)$ & $2.193(1.466-3.28 I)$ & $3.620(1.357-9.660)$ \\
\hline & & 0.000 & $0.000^{\mathrm{a}}$ & 0.001 & 0.000 & $0.010^{\mathrm{a}}$ \\
\hline \multirow[t]{2}{*}{ Asian } & $466 / 460$ & 0.291 (0.745-I.I40) & $0.940(0.564-1.566)$ & $0.876(0.664-\mathrm{I} . \mathrm{I} 56)$ & $0.887(0.682-1.152)$ & $0.986(0.598-1.627)$ \\
\hline & & 0.451 & $0.000^{\mathrm{a}}$ & 0.088 & 0.368 & $0.956^{a}$ \\
\hline \multicolumn{7}{|l|}{ Tumor type } \\
\hline \multirow[t]{2}{*}{ ALL } & $54 / 58$ & $2.264(1.097-4.665)$ & $4.182(0.416-42.000)$ & $2.281(0.953-5.462)$ & $2.439(1.055-5.642)$ & $3.353(0.338-33.259)$ \\
\hline & & $0.029 *$ & 0.224 & 0.064 & $0.037^{*}$ & 0.301 \\
\hline \multirow[t]{2}{*}{ CLL } & $126 / 108$ & $0.608(0.395-0.938)$ & $0.496(0.03 \mid-8.060)$ & $0.762(0.469-1.238)$ & $0.762(0.469-1.238)$ & $0.548(0.034-8.852)$ \\
\hline & & $0.025^{*}$ & 0.622 & 0.272 & 0.272 & 0.672 \\
\hline \multirow[t]{2}{*}{ AML } & $35 / 110$ & $0.965(0.79 \mid-I .176)$ & $0.988(0.604-1.618)$ & $0.933(0.722-1.206)$ & $0.94 I(0.738-I .20 I)$ & $1.026(0.633-1.663)$ \\
\hline & & $0.72 \mathrm{I}^{\mathrm{a}}$ & $0.963^{\mathrm{a}}$ & $0.595^{\mathrm{a}}$ & $0.626^{a}$ & $0.918^{a}$ \\
\hline \multirow[t]{2}{*}{ CML } & $35 / 110$ & $2.303(0.839-2.084)$ & $5.832(1.355-25.098)$ & $2.631(1.138-6.084)$ & $2.910(1.304-6.496)$ & $3.866(0.966-15.477)$ \\
\hline & & $0.229^{a}$ & $0.018^{\mathrm{a}, *}$ & $0.024^{\mathrm{a}, *}$ & $0.009^{\mathrm{a}, *}$ & $0.056^{\mathrm{a}}$ \\
\hline \multirow[t]{2}{*}{$\mathrm{NHL}$} & $499 / 675$ & $1.263(1.27|-| .682)$ & I.057 (0.525-2.I25) & $1.525(0.983-2.366)$ & $\mathrm{I} .477(0.96 \mathrm{I}-2.272)$ & $0.903(0.452-1.804)$ \\
\hline & & $0.164^{\mathrm{a}}$ & $0.877^{\mathrm{a}}$ & 0.060 & 0.075 & $0.772^{\mathrm{a}}$ \\
\hline \multirow[t]{2}{*}{$\mathrm{HL}$} & $94 / 352$ & $1.508(1.050-2.166)$ & $3.798(1.628-8.858)$ & I.086 (0.658-I.792) & I.33। (0.836-2.II9) & 3.703 (1.619-8.467) \\
\hline & & $0.026 *$ & $0.002^{\mathrm{a}, *}$ & 0.747 & 0.228 & $0.002^{\mathrm{a}, *}$ \\
\hline \multirow[t]{2}{*}{ MM } & $265 / 348$ & I.204 (0.53I-2.728) & $6.107(2.224-16.771)$ & I.344 (0.564-3.202) & $1.432(0.567-3.612)$ & $4.038(1.550-10.523)$ \\
\hline & & 0.657 & $0.000^{\mathrm{a}, *}$ & 0.504 & 0.447 & $0.004^{\mathrm{a}, *}$ \\
\hline
\end{tabular}

Notes: ${ }^{a} \mathrm{~A}$ fixed effects model was used when the $P$-value for Cochran's $Q$ test for heterogeneity was more than 0.1 . Otherwise, a random effects model was used. $* P<0.05$.

Abbreviations: ALL, acute lymphoblastic leukemia; CLL, chronic lymphocytic leukemia; AML, acute myeloid leukemia; CML, chronic myeloid leukemia; HL, Hodgkin's lymphoma; NHL, non-Hodgkin's lymphoma; MM, multiple myeloma; OR, odds ratio; Cl, confidence interval. 
Studies

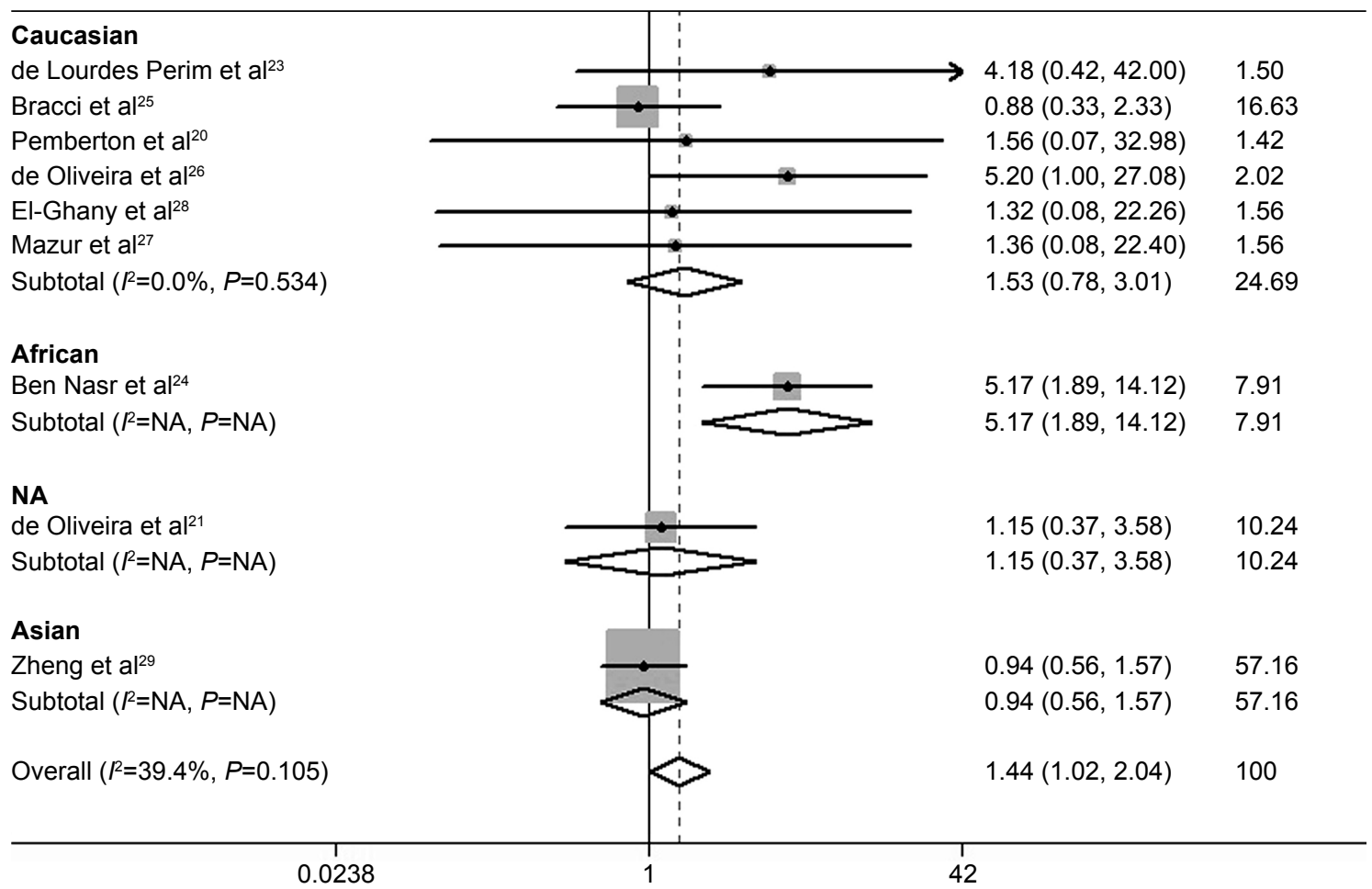

Figure 3 Subgroup analysis of the association between SDFI-3'A polymorphism and the risk of hematological malignancy in different ethnicities under a homozygote genetic model (AA vs GG).

Abbreviations: $\mathrm{OR}$, odds ratio; $\mathrm{Cl}$, confidence interval; $\mathrm{NA}$, not available.

GWASs concerning hematological malignancy after searching all known GWAS databases, such as GWAS Central. The reason may be that GWAS cannot identify all of the SNPs involved in a single action. ${ }^{39} \mathrm{Up}$ to now, the reports concerning the relationship between $S D F 1-3^{\prime}$ A polymorphism and the risk of hematological malignancy have all mostly been based on the small-scale case-control studies. ${ }^{20,21,23-29}$ Furthermore, the results from these studies are still somewhat controversial. ${ }^{21,24}$ Therefore, we conducted a meta-analysis to combine the results of published case-control studies to further explain their controversy.

Although several meta-analyses have been performed to evaluate the relationship between $S D F 1-3^{\prime}$ A polymorphism and the risk of cancer previously, ${ }^{40-43}$ as far as we know, this meta-analysis was the first to pool published studies to estimate the relationship between the SDF1-3'A polymorphism and the risk of hematological malignancy. The result suggested that for all types of hematological cancer, $S D F 1-3$ 'A polymorphism, especially AA genotype, was associated with increased risk of hematological cancer, which is consistent with findings in some types of solid tumors, such as breast cancer and lung cancer. ${ }^{40}$ However, SDF1-3'A polymorphism was not associated with the risk of hematological cancer in the Caucasian subgroup. This result is not consistent with the results of other meta-analyses ${ }^{41,42}$ and the distinction may be attributed to the difference in tumor type. In addition, subgroup analysis by hematological cancer type also found that AA genotype only increased the incidence of some types of hematological cancer, but did not influence all types of hematological cancer. More specifically, our study found that AA genotype was associated with increased risk of $\mathrm{HL}$ and $\mathrm{MM}$, which is consistent with previous findings. ${ }^{24,27}$ For AML, SDF1-3'A polymorphism was not associated with increased risk of AML, which was in agreement with Zheng et al's finding. ${ }^{29}$ For CML, we found that $S D F 1-3^{\prime}$ A polymorphism was connected with increased risk of CML, which was similar to de Oliveira et al's finding. ${ }^{26}$ For NHL, no association between SDF1-3'A polymorphism and the risk of NHL was found, and the result was not in agreement with a previous study in an HIV-infected population. ${ }^{42}$ The reason, we speculated, may be that HIV-infection significantly altered the frequency of genotypes (AA, AG, and GG) in the population. ${ }^{44,45}$

Like other meta-analyses, several shortcomings exist in this study. Firstly, only a total of 3,250 subjects (1,576 cases and 1,674 healthy controls) were involved in this meta-analysis and there is not enough strength to estimate 


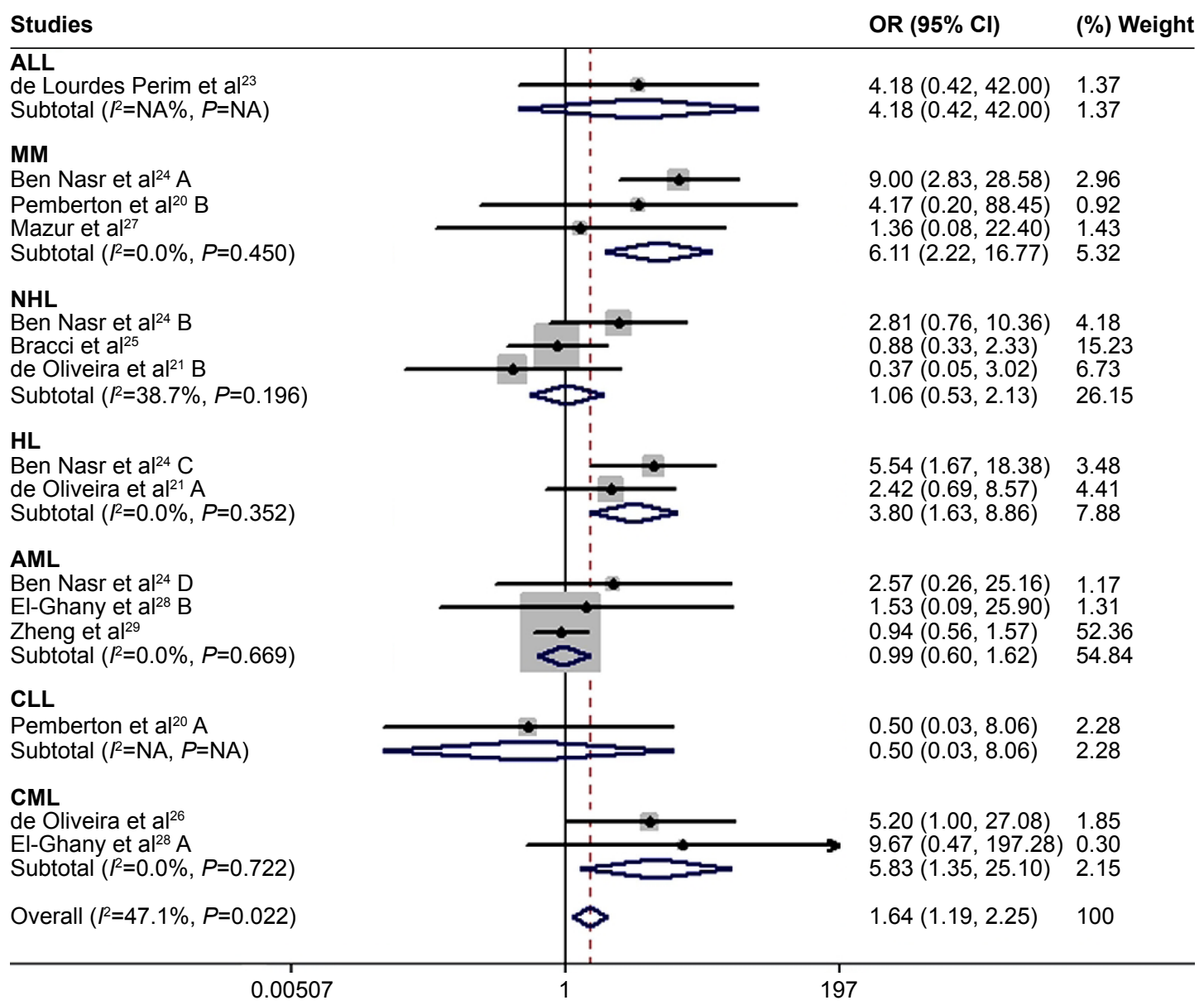

Figure 4 Subgroup analysis of the association between SDFI-3'A polymorphism and the risk of different types of hematological malignancy under a homozygote genetic model (AA vs GG).

Abbreviations: ALL, acute lymphoblastic leukemia; CLL, chronic lymphocytic leukemia; AML, acute myeloid leukemia; CML, chronic myeloid leukemia; HL, Hodgkin's lymphoma; NHL, non-Hodgkin's lymphoma; MM, multiple myeloma; OR, odds ratio; Cl, confidence interval.

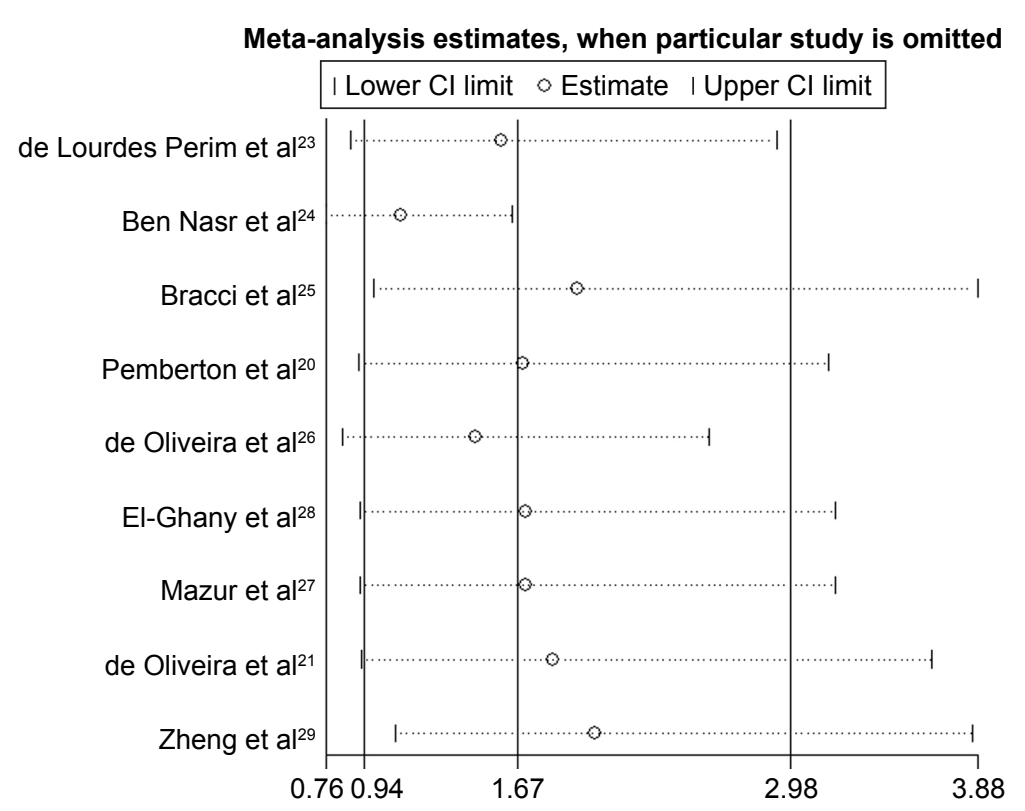

Figure 5 Sensitivity analysis of the relationships of SDFI-3'A polymorphism with the risk of hematological malignancy. Abbreviation: $\mathrm{Cl}$, confidence interval. 


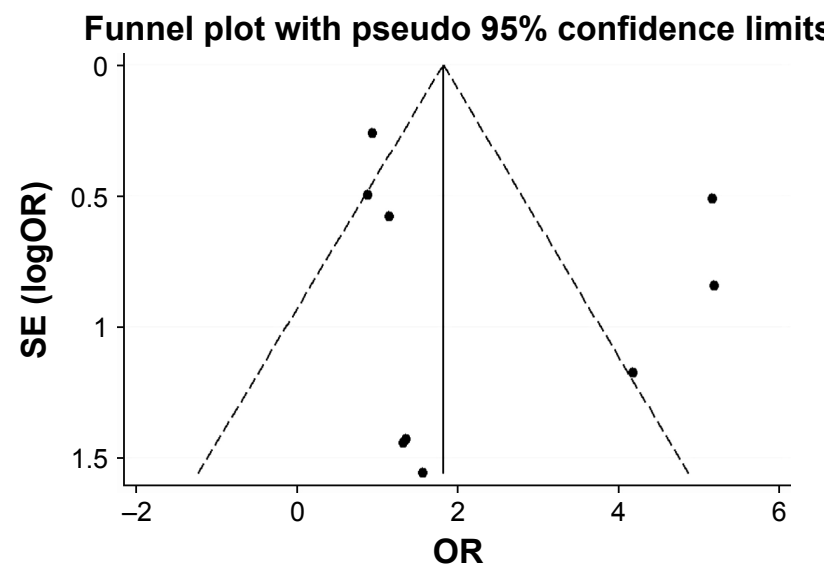

Figure 6 Funnel plot of SDFI-3'A polymorphism and the risk of hematological malignancy under a homozygote genetic model (AA vs GG).

Abbreviations: SE, standard error; OR, odds ratio.

the association between the $S D F 1-3^{\prime}$ A polymorphism and the risk of hematological cancer due to relatively small sample size. Therefore, the strength of this meta-analysis should be further demonstrated by more large scale casecontrol studies. Secondly, most studies included in this meta-analysis were conducted in Caucasians, and the data from Africans and Asians are less. More importantly, the frequency of $S D F 1-3^{\prime} \mathrm{A}$ polymorphism ranges widely across different ethnic groups, ${ }^{46}$ therefore, more studies should be performed in Africans and Asians to confirm the result of this meta-analysis. Finally, besides genetic polymorphism, the environmental factors or the interaction of genetic and environmental factors also influenced the results. However, we cannot assess their effect on the pooled results because information related to environmental factors was not available in the literature. Therefore, this is another limitation of this study that we must acknowledge.

\section{Conclusion}

In conclusion, our meta-analysis demonstrates that $S D F 1-3^{\prime} \mathrm{A}$ polymorphism may be associated with increased risk of hematological malignancy, especially for CML, HL, MM, and the non-Caucasian population. These conclusions should be reconfirmed by more evidence from large sample sized studies.

\section{Acknowledgment}

This work was supported by 2013 Liaoning Climbing Scholar Foundation.

\section{Disclosure}

The authors report no conflicts of interest in this work.

\section{References}

1. Siegel RL, Miller KD, Jemal A. Cancer statistics, 2016. CA Cancer J Clin. 2016;66(1):7-30.

2. Rampal R, Levine RL. Leveraging cancer genome information in hematologic malignancies. J Clin Oncol. 2013;31(15):18851892.

3. Torre LA, Bray F, Siegel RL, Ferlay J, Lortet-Tieulent J, Jemal A. Global cancer statistics, 2012. CA Cancer J Clin. 2015;65(2):87-108.

4. Chung YR, Schatoff E, Abdel-Wahab O. Epigenetic alterations in hematopoietic malignancies. Int J Hematol. 2012;96(4):413-427.

5. Horsboel TA, De Thurah A, Nielsen B, Nielsen CV. Factors associated with work outcome for survivors from haematological malignancies a systematic literature review. Eur J Cancer Care (Engl). 2012; 21(4):424-435.

6. Le Y, Zhou Y, Iribarren P, Wang J. Chemokines and chemokine receptors: their manifold roles in homeostasis and disease. Cell Mol Immunol. 2004;1(2):95-104.

7. Graham GJ, Locati M. Regulation of the immune and inflammatory responses by the 'atypical' chemokine receptor D6. J Pathol. 2013; 229(2):168-175.

8. Wang J, Knaut H. Chemokine signaling in development and disease. Development. 2014;141(22):4199-4205.

9. Karin N. The multiple faces of CXCL12 (SDF-1alpha) in the regulation of immunity during health and disease. J Leukoc Biol. 2010;88(3): 463-473.

10. Chen $\mathrm{H}, \mathrm{Xu} \mathrm{X}, \mathrm{Teng} \mathrm{J}$, et al. CXCR4 inhibitor attenuates allergeninduced lung inflammation by down-regulating MMP-9 and ERK1/2. Int J Clin Exp Pathol. 2015;8(6):6700-6707.

11. Suratt BT, Petty JM, Young SK, et al. Role of the CXCR4/SDF-1 chemokine axis in circulating neutrophil homeostasis. Blood. 2004; 104(2):565-571.

12. Cavallaro S. CXCR4/CXCL12 in non-small-cell lung cancer metastasis to the brain. Int J Mol Sci. 2013;14(1):1713-1727.

13. Kalinkovich A, Tavor S, Avigdor A, et al. Functional CXCR4-expressing microparticles and SDF-1 correlate with circulating acute myelogenous leukemia cells. Cancer Res. 2006;66(22):11013-11020.

14. Möhle R, Schittenhelm M, Failenschmid C, et al. Functional response of leukaemic blasts to stromal cell-derived factor-1 correlates with preferential expression of the chemokine receptor CXCR4 in acute myelomonocytic and lymphoblastic leukaemia. Br J Haematol. 2000; 110(3):563-572.

15. Möhle R, Failenschmid C, Bautz F, Kanz L. Overexpression of the chemokine receptor CXCR4 in B cell chronic lymphocytic leukemia is associated with increased functional response to stromal cell-derived factor-1 (SDF-1). Leukemia. 1999;13(12):1954-1959.

16. Wen Q, Chen RL, Cai KR, Lin YW. [Level of SDF-1/CXCR4 in children with acute leukemia and its significance]. Zhongguo Shi Yan Xue Ye Xue Za Zhi. 2011;19(2):324-326. Chinese.

17. Zhang C, Cui GH, Liu F, Wu QL, Chen Y. [The role of stromal cell derived factor-1/CXCR4 biological axis in tumor metastasis of nonHodgkin lymphoma]. Zhonghua Yi Xue Za Zhi. 2007;87(10):695-697. Chinese.

18. Zhang XH, Fu JX, Zhang JH, Zhang YM. [Study of biological behavior of stromal cell-derived factor-1 on multiple myeloma cell migration and adhesion]. Zhonghua Xue Ye Xue Za Zhi. 2006;27(4):240-243.

19. Winkler C, Modi W, Smith MW, et al. Genetic restriction of AIDS pathogenesis by an SDF-1 chemokine gene variant. ALIVE Study, Hemophilia Growth and Development Study (HGDS), Multicenter AIDS Cohort Study (MACS), Multicenter Hemophilia Cohort Study (MHCS), San Francisco City Cohort (SFCC). Science. 1998;279(5349): 389-393.

20. Pemberton NC, Paneesha S, Hiller L, et al. The SDF-1 G>A polymorphism at position 801 plays no role in multiple myeloma but may contribute to an inferior cause-specific survival in chronic lymphocytic leukemia. Leuk Lymphoma. 2006;47(7):1239-1244.

21. de Oliveira KB, Oda JM, Voltarelli JC, et al. CXCL12 rs1801157 polymorphism in patients with breast cancer, Hodgkin's lymphoma, and non-Hodgkin's lymphoma. J Clin Lab Anal. 2009;23(6):387-393. 
22. Stang A. Critical evaluation of the Newcastle-Ottawa scale for the assessment of the quality of nonrandomized studies in meta-analyses. Eur J Epidemiol. 2010;25(9):603-605.

23. de Lourdes Perim A, Guembarovski RL, Oda JM, et al. CXCL12 and TP53 genetic polymorphisms as markers of susceptibility in a Brazilian children population with acute lymphoblastic leukemia (ALL). Mol Biol Rep. 2013;40(7):4591-4596.

24. Ben Nasr M, Reguaya Z, Berraies L, et al. Association of stromal cell-derived factor-1-3'A polymorphism to higher mobilization of hematopoietic stem cells CD34+ in Tunisian population. Transplant Proc. 2011;43(2):635-638.

25. Bracci PM, Skibola CF, Conde L, et al. Chemokine polymorphisms and lymphoma: a pooled analysis. Leuk Lymphoma. 2010;51(3):497-506.

26. de Oliveira CE, Cavassin GG, Perim Ade L, et al. Stromal cell-derived factor-1 chemokine gene variant in blood donors and chronic myelogenous leukemia patients. J Clin Lab Anal. 2007;21(1):49-54.

27. Mazur G, Gębura K, Gieryng A, Butrym A, Wróbel T, Bogunia-Kubik K The CXCL12-3'A allele plays a favourable role in patients with multiple myeloma. Cytokine. 2013;64(1):422-426.

28. El-Ghany HM, El-Saadany ZA, Bahaa NM, Ibrahim NY, Hussien SM. Stromal cell derived factor-1 (CXCL12) chemokine gene variant in myeloid leukemias. Clin Lab. 2014;60(5):735-741.

29. Zheng Q, Shuai X, Ye Y, et al. The role of polymorphisms of stromal-derived factor- 1 and $\mathrm{CXC}$ receptor 4 in acute myeloid leukemia and leukemia cell dissemination. Gene. 2016 ; 588(2):103-108.

30. Shirozu M, Nakano T, Inazawa J, et al. Structure and chromosomal localization of the human stromal cell-derived factor 1 (SDF1) gene. Genomics. 1995;28(3):495-500.

31. Zmetakova I, Danihel L, Smolkova B, et al. Evaluation of protein expression and DNA methylation profiles detected by pyrosequencing in invasive breast cancer. Neoplasma. 2013;60(6):635-646.

32. Imai H, Sunaga N, Shimizu Y, et al. Clinicopathological and therapeutic significance of CXCL12 expression in lung cancer. Int J Immunopathol Pharmacol. 2010;23(1):153-164.

33. Yang DL, Xin MM, Wang JS, et al. Chemokine receptor CXCR4 and its ligand CXCL12 expressions and clinical significance in bladder cancer. Genet Mol Res. 2015;14(4):17699-17707.

34. de Oliveira KB, Guembarovski RL, Oda JM, et al. CXCL12 rs1801157 polymorphism and expression in peripheral blood from breast cancer patients. Cytokine. 2011;55(2):260-265.
35. Theodoropoulos GE, Panoussopoulos GS, et al. Analysis of the stromal cell-derived factor $1-3^{\prime} \mathrm{A}$ gene polymorphism in pancreatic cancer. Mol Med Rep. 2010;3(4):693-698.

36. Lee YL, Kuo WH, Lin CW, et al. Association of genetic polymorphisms of CXCL12/SDF1 gene and its receptor, CXCR4, to the susceptibility and prognosis of non-small cell lung cancer. Lung Cancer. 2011;73(2):147-152.

37. Kruszyna L, Lianeri M, Rydzanicz M, Szyfter K, Jagodziński PP. SDF1-3' a gene polymorphism is associated with laryngeal cancer. Pathol Oncol Res. 2010;16(2):223-227.

38. Enjuanes A, Benavente $\mathrm{Y}$, Bosch F, et al. Genetic variants in apoptosis and immunoregulation-related genes are associated with risk of chronic lymphocytic leukemia. Cancer Res. 2008;68(24):10178-10186.

39. Wu N, Zhang X, Jia P, Jia D. Lack of an Association between the SDF-1 rs1801157 Polymorphism and Coronary Heart Disease: A MetaAnalysis. Sci Rep. 2015;5:11803.

40. Gong H, Tan M, Wang Y, et al. The CXCL12 G801A polymorphism and cancer risk: evidence from 17 case-control studies. Gene. 2012;509(2):228-231.

41. Zhu K, Jiang B, Hu R, et al. The CXCL12 G801A polymorphism is associated with cancer risk: a meta-analysis. PLoS One. 2014;9(9):e108953.

42. Meng D, Wu YX, Heerah V, et al. CXCL12 G801A polymorphism and cancer risk: An updated meta-analysis. J Huazhong Univ Sci Technolog Med Sci. 2015;35(3):319-326.

43. Rabkin CS, Yang Q, Goedert JJ, Nguyen G, Mitsuya H, Sei S. Chemokine and chemokine receptor gene variants and risk of nonHodgkin's lymphoma in human immunodeficiency virus-1-infected individuals. Blood. 1999;93(6):1838-1842.

44. Su B, Jin L, Hu F, et al. Distribution of two HIV-1-resistant polymorphisms (SDF1-3'A and CCR2-64I) in East Asian and world populations and its implication in AIDS epidemiology. Am J Hum Genet. 1999;65(4):1047-1053.

45. Apostolakis S, Baritaki S, Krambovitis E, Spandidos DA. Distribution of HIV/AIDS protective SDF1, CCR5 and CCR2 gene variants within Cretan population. J Clin Virol. 2005;34(4):310-314.

46. Nookhai S, Ruxrungtham K, Phanuphak P, Oelrichs R. Prevalence of CCR2-64I, SDF1-3'A and CCR5-Delta32 alleles in healthy Thais. Eur J Immunogenet. 2000;27(3):153-157.
OncoTargets and Therapy

\section{Publish your work in this journal}

OncoTargets and Therapy is an international, peer-reviewed, open access journal focusing on the pathological basis of all cancers, potential targets for therapy and treatment protocols employed to improve the management of cancer patients. The journal also focuses on the impact of management programs and new therapeutic agents and protocols on

\section{Dovepress}

patient perspectives such as quality of life, adherence and satisfaction. The manuscript management system is completely online and includes a very quick and fair peer-review system, which is all easy to use. Visit http://www.dovepress.com/testimonials.php to read real quotes from published authors. 